\title{
The Inadvertent Activation of Silicate Minerals Flotation and Their Depression in Molybdenite Beneficiation
}

\author{
Yu Miao ${ }^{1}$, Tao Long ${ }^{2}$, Jingjun Wang ${ }^{1}$, Fu Lai $^{1}$, Weiran Zuo ${ }^{3}$ (D) and Bao Guo ${ }^{3, *(D)}$ \\ 1 China Gold Inner Mongolia Mining Co., Ltd., Manzhouli 021400, China; 18510335243@139.com (Y.M.); \\ 13088504483@139.com (J.W.); 15049778581@163.com (F.L.) \\ 2 China National Gold Group Co., Ltd., Beijing 100020, China; 13051868998@139.com \\ 3 School of Zijin Geology and Mining Engineering, Fuzhou University, Fuzhou 350108, China; \\ zuoweiran@163.com \\ * Correspondence: guobao@fzu.edu.cn
}

Citation: Miao, Y.; Long, T.; Wang, J.; Lai, F.; Zuo, W.; Guo, B. The Inadvertent Activation of Silicate Minerals Flotation and Their Depression in Molybdenite Beneficiation. Minerals 2021, 11, 1296. https://doi.org/10.3390/min11111296

Academic Editors: Siyuan Yang, Yangge Zhu, Cheng Liu, Yanhong Wang and Przemyslaw B. Kowalczuk

Received: 9 October 2021

Accepted: 17 November 2021

Published: 22 November 2021

Publisher's Note: MDPI stays neutral with regard to jurisdictional claims in published maps and institutional affiliations.

Copyright: (c) 2021 by the authors. Licensee MDPI, Basel, Switzerland. This article is an open access article distributed under the terms and conditions of the Creative Commons Attribution (CC BY) license (https:// creativecommons.org/licenses/by/ $4.0 /)$.

\begin{abstract}
The Wushan Operation has been studied as a case study, particularly relevant to the copper-molybdenum separation circuit, in which efforts have been made to improve the quality of the molybdenum concentrate through diagnostic analysis. A key finding has been the appearance of coarser silicate minerals in the molybdenum concentrate due to their inadvertent activation in flotation. The suitable silicate minerals flotation conditions occurs, most likely, due to upstream bulk flotation regarding the usage of novel collectors and metal cations bearing process water. The flotation of silicate minerals can be diminished by the implementation of water glass and regrinding. The mechanisms underlying flotation behaviors have been revealed by using advanced in-situ surface analysis and particle size analysis techniques.
\end{abstract}

Keywords: molybdenite; flotation; silicate minerals; activation; regrinding

\section{Introduction}

Porphyry $\mathrm{Cu}-\mathrm{Mo}$ ores are important resources for the extraction of molybdenum. In porphyry $\mathrm{Cu}-\mathrm{Mo}$ ores, copper and molybdenum mainly exist in the form of chalcopyrite and molybdenite. As a valuable mineral, it is of great significance to efficiently separate molybdenite from chalcopyrite. Commonly, the molybdenite beneficiation is accomplished by means of $\mathrm{Cu}-\mathrm{Mo}$ bulk flotation, followed by separative flotation of molybdenite from chalcopyrite by using depressants, conventionally sodium sulfide or sodium hydrosulfide to depress the flotation of copper sulfide [1-5]. The undesirable presence of copper in the molybdenum concentrate was a central focus for researchers and attracted plenty of the investigators' attentions with some successful operational applications [6,7]. Recovery of gangue minerals also deteriorated the grade of molybdenum concentrate. Apart from mineralogically associated gangue, the liberated pyrite and silicate minerals are also floatable to some extent under certain flotation conditions. In particular, the flotation of quartz can usually be activated by metal cations as shown in a lot of investigations [8-10]. However, there is little research on the flotation behaviors of silicate minerals in molybdenite beneficiation. As gangue minerals, the flotation of silicate minerals might be activated inadvertently, which needs to be investigated by revealing the surface properties.

The copper-molybdenum operation of Wushan, located in Manzhouli, Inner Mongolia Autonomous Region, Northeast China, was selected as a case study in this study. Over the past period, the Mo grade has been continuously lower than $45 \%$ with $\mathrm{Cu}$ grade being controlled to less than $1.5 \%$. Therefore, the product quality cannot be guaranteed resulting in the economic loss of the operation. This paper presents solutions from different aspects, including surface property and particle size, to address the problem. Significant improvement of the product quality was achieved based on experimental studies and 
plant practices. The mechanisms underlying the inadvertent activation of silicate minerals flotation was recognized and depressed in molybdenite beneficiation.

\section{Problem Statement of Wushan Operation}

\subsection{Flowsheet of Wushan Processing Operation}

The Wushan copper-molybdenum operation was put into commission in 2009. A typical copper-molybdenum flowsheet has been applied to the plant to produce separate copper and molybdenum concentrates through bulk flotation and separation flotation, in a stepwise fashion. The flotation at the $\mathrm{Cu}$-Mo separation stage consists of one stage of rougher flotation, six stages of cleaner flotation and three stages of scavenger flotation, as shown in Figure 1. A kerosene dosage of $0.35 \mathrm{~kg} / \mathrm{t}$ and a NaHS dosage of $17 \mathrm{~kg} / \mathrm{t}$ were "stepwisely" added at different stage of Cu-Mo separation flotation.

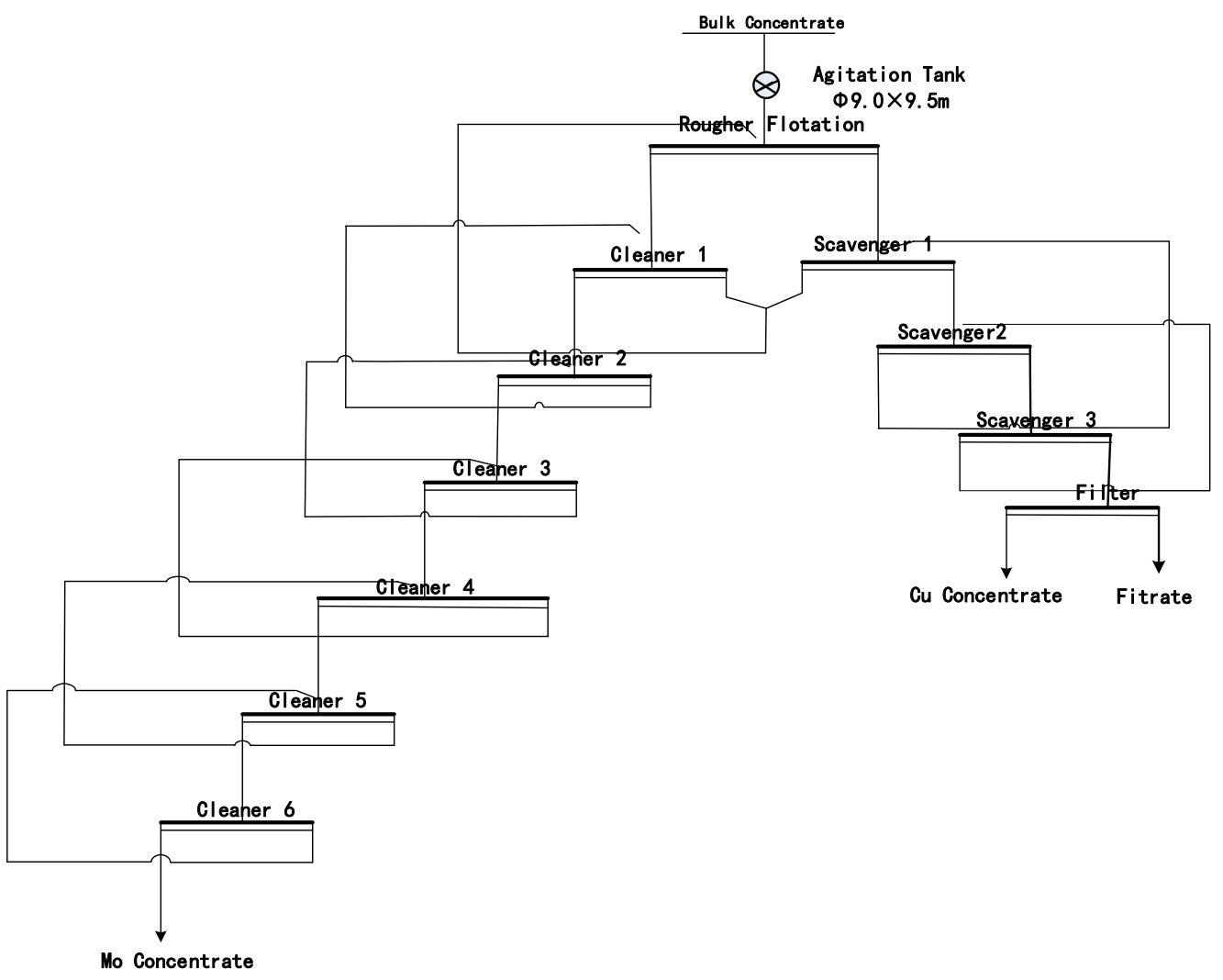

Figure 1. Flow sheet of the Cu-Mo separation flotation circuit at Wushan Operation.

Currently, the feed input at the bulk flotation stage is 84,500 ton/day, $30 \%$ higher than its designed value, producing 6000 ton of Mo per year in the form of molybdenum concentrate. Recently, novel copper flotation collectors have been introduced into the bulk flotation to improve production efficiency and eco-friendly of the operation.

\subsection{Product Quality Analysis}

Product quality analysis has been regularly applied to molybdenum concentrate with $\mathrm{Cu}, \mathrm{Mo}, \mathrm{Fe}, \mathrm{S}, \mathrm{SiO}_{2}$ being the major considerable. The selected results of 10 different samples over a period of production are shown in Table 1. It is seen that only the second samples meet the criteria (GB3200-89: $\mathrm{Mo} \geq 45 \%, \mathrm{Cu} \leq 1.5 \%$ ). Though $\mathrm{Cu} \leq 2.5 \%$ is acceptable, excessive $\mathrm{SiO}_{2}$ should be the main problem for product quality. Table 1 indicates that significant amounts of $\mathrm{SiO}_{2}(\geq 20 \%)$ have been transferred into the concentrate. Since molybdenite $\left(\mathrm{MoS}_{2}\right)$ and silicate (assayed in the form of $\mathrm{SiO}_{2}$ ) jointly contributed to more than $95 \%$ mass content for all concentrate samples, the higher grade of $\mathrm{SiO}_{2}$ present in 
the concentrate, the lower grade of Mo. Therefore, the depression of molybdenite can be specifically due to the inadvertent flotation of the silicates.

Table 1. The grade of Mo concentrate from various samples.

\begin{tabular}{cccc}
\hline \multirow{2}{*}{ Sample No. } & \multicolumn{3}{c}{ Grade, $\%$} \\
\cline { 2 - 4 } & $\mathbf{C u}$ & $\mathbf{M o}$ & $\mathbf{S i O}_{\mathbf{2}}$ \\
\hline 1 & 1.76 & 53.01 & 9.23 \\
2 & 1.14 & 45.41 & 26.01 \\
3 & 1.25 & 44.30 & 27.14 \\
4 & 2.44 & 43.78 & 35.16 \\
5 & 2.47 & 43.72 & 19.66 \\
6 & 1.37 & 43.37 & 31.02 \\
7 & 1.38 & 40.23 & 37.76 \\
8 & 2.08 & 38.64 & 31.69 \\
9 & 1.68 & 38.12 & 43.92 \\
10 & 1.63 & 36.95 & 40.55 \\
\hline
\end{tabular}

Size by size analysis was carried out for both Cu-Mo separation feed and Mo concentrate after screening and subsequent assaying. It can be seen from Table 2 that the $\mathrm{Cu}-\mathrm{Mo}$ separation feed during the unqualified period is obviously coarser. The mass fraction of -600 mesh is $29.06 \%$ during the unqualified period, while it is $44.18 \%$ during the qualified period. During unqualified period, $72.18 \%$ of $\mathrm{SiO}_{2}$ is distributed in +325 mesh fraction, while this value decreases to $59.44 \%$ during the qualified period. On the other hand, the grades of $\mathrm{SiO}_{2}$ in both feeds are basically the same as $20.04 \%$ and $20.15 \%$, respectively.

Table 2. Size-by-size analysis of Cu-Mo separation feed.

\begin{tabular}{|c|c|c|c|c|c|c|c|}
\hline \multirow{3}{*}{ Size, $\mu \mathrm{m}$} & \multirow{3}{*}{ Mesh } & \multicolumn{3}{|c|}{ Unqualified Period } & \multicolumn{3}{|c|}{ Qualified Period } \\
\hline & & \multirow{2}{*}{ Mass, $\%$} & \multicolumn{2}{|c|}{$\mathrm{SiO}_{2}$} & \multirow{2}{*}{ Mass, $\%$} & \multicolumn{2}{|c|}{$\mathrm{SiO}_{2}$} \\
\hline & & & Grade, \% & Distribution, $\%$ & & Grade, \% & Distribution, $\%$ \\
\hline$\geq 74$ & +200 & 30.51 & 36.44 & 55.48 & 17.1 & 48.23 & 40.93 \\
\hline $7 \overline{4} \sim 43$ & $200 \sim 325$ & 22.14 & 15.12 & 16.7 & 17.22 & 21.66 & 18.51 \\
\hline $43 \sim 20$ & $325 \sim 600$ & 18.29 & 12.68 & 11.57 & 21.5 & 11.81 & 12.6 \\
\hline$\leq 20$ & -600 & 29.06 & 11.2 & 16.24 & 44.18 & 12.76 & 27.97 \\
\hline Sum & & 100 & 20.04 & 100 & 100 & 20.15 & 100 \\
\hline
\end{tabular}

In respect of the Mo concentrate, $76.88 \%$ of $\mathrm{SiO}_{2}$ is distributed in the +325 mesh fraction, while this value is only $36.34 \%$ during the qualified period (Table 3 ). Such a difference is of greater significance than it behaves in the feed, which means the coarser silicate minerals are more likely transferred into concentrate. This leads to $\mathrm{SiO}_{2}$ grade of $26.3 \%$ during the qualified period, but $42.2 \%$ during the unqualified period.

Table 3. Size-by-size analysis of Mo concentrate.

\begin{tabular}{|c|c|c|c|c|c|c|c|c|c|c|c|}
\hline \multirow{3}{*}{ Size, $\mu \mathrm{m}$} & \multirow{3}{*}{ Mesh } & \multicolumn{5}{|c|}{ Unqualified Period } & \multicolumn{5}{|c|}{ Qualified Period } \\
\hline & & \multirow{2}{*}{ Mass, $\%$} & \multicolumn{2}{|c|}{ Grade $\%$} & \multicolumn{2}{|c|}{ Distribution, $\%$} & \multirow{2}{*}{ Mass, \% } & \multicolumn{2}{|c|}{ Grade, $\%$} & \multicolumn{2}{|c|}{ Distribution, $\%$} \\
\hline & & & Mo & $\mathrm{SiO}_{2}$ & Mo & $\mathrm{SiO}_{2}$ & & Mo & $\mathrm{SiO}_{2}$ & Mo & $\mathrm{SiO}_{2}$ \\
\hline 43 & +325 & 53.17 & 25.96 & 61.04 & 37.55 & 76.88 & 39.76 & 47.77 & 30.66 & 38.7 & 46.34 \\
\hline $43 \sim 20$ & $325 \sim 600$ & 26.18 & 46.2 & 26.57 & 32.9 & 16.48 & 31.76 & 49.15 & 28.45 & 31.81 & 34.35 \\
\hline$\leq 20$ & -600 & 20.65 & 52.58 & 13.57 & 29.54 & 6.64 & 28.48 & 50.83 & 17.83 & 29.49 & 19.3 \\
\hline Sum & & 100 & 36.8 & 42.2 & 100 & 100 & 100 & 49.1 & 26.3 & 100 & 100 \\
\hline
\end{tabular}


Therefore, it can be deduced that coarse and floatable silicate minerals are present in the $\mathrm{Cu}-\mathrm{Mo}$ separation flotation, and the enrichment of these coarse-grained gangue particles is the major reason for the low-quality production.

\subsection{Process Mineralogical Analysis}

The Wushan Operation carries out quantitative mineralogy routinely for bulk, copper and molybdenum concentrate, respectively. Concentrates are examined to determine the abundance of each type of minerals in each size fraction as well as the liberation of the interesting minerals. Combining the mineralogical information with the plant operating conditions is helpful to optimize the process performance.

Table 4 shows the mineralogical composition of the $\mathrm{Cu}$-Mo separation feed. It contains chalcopyrite as the main copper-bearing mineral, molybdenite as the main molybdeumbearing mineral and pyrite as the most abundant alternative sulfide mineral. The main gangue minerals in the feed are quartz and feldspar.

Table 4. Mineralogical composition of Cu-Mo separation feed, \%.

\begin{tabular}{cc}
\hline Minerals & Volume, $\%$ \\
\hline Molybdenite & 5.67 \\
Chalcopyrite & 39.83 \\
Covellite & 5.96 \\
Chalcocite & 1.12 \\
Bornite & 5.36 \\
Tennantite & 3.41 \\
Pyrite & 15.83 \\
Sphalerite & 2.21 \\
Iron oxide mineral & 1.43 \\
Quartz & 9.11 \\
Potash feldspar, Plagioclase & 6.46 \\
Muscovite, Biotite & 1.82 \\
Others & 1.77 \\
Sum & 100.00 \\
\hline
\end{tabular}

Most copper minerals in the feed are liberated, accounting for $86.26 \%$ (Table 5). Its association with molybdenite is very minor, accounting for only $1.17 \%$, making $\mathrm{Cu}-\mathrm{Mo}$ separation easily accomplished. Regrinding of the feed seems therefore unnecessary to avoid copper minerals in Mo concentrate. Most of molybdenite is also liberated, accounting for $82.17 \%$ of the total feed (Table 5). According to the microscopic images in Figure 2, molybdenite particles in the feed have no significant interlocking with other minerals and their blade-shaped grains have reached the desired degree of liberation. In general, most sulfide minerals are liberated and barely associated with silicate minerals. A certain amount of pyrite and sphalerite $(15.83 \%$ and $2.21 \%$, respectively, see Table 4$)$ are present in Cu-Mo separation feed. Although the interlocking of silicate minerals with pyrite and sphalerite might exist at a small extent, it is not the major cause of silicate minerals' access to molybdenum concentrate. Attempts at increasing the NaHS dosage have been done by the authors to depress sulfide minerals as much as possible, however, the recovery of silicate minerals seemed to not be affected. Therefore, minerals association can hardly devote to the occurrence of silicate minerals in flotation concentrate.

Table 5. Copper and molybdenum minerals dissemination of $\mathrm{Cu}-\mathrm{Mo}$ separation feed, $\%$.

\begin{tabular}{ccccccc}
\hline Minerals & Liberated & Mo/Cu Minerals & Sulfide & Oxide & Gangue & Interlocked \\
\hline Copper & 86.26 & 1.17 & 5.98 & 0.32 & 3.77 & 2.50 \\
Molybdenum & 82.17 & 7.11 & 4.86 & 0.15 & 3.64 & 2.07 \\
\hline
\end{tabular}



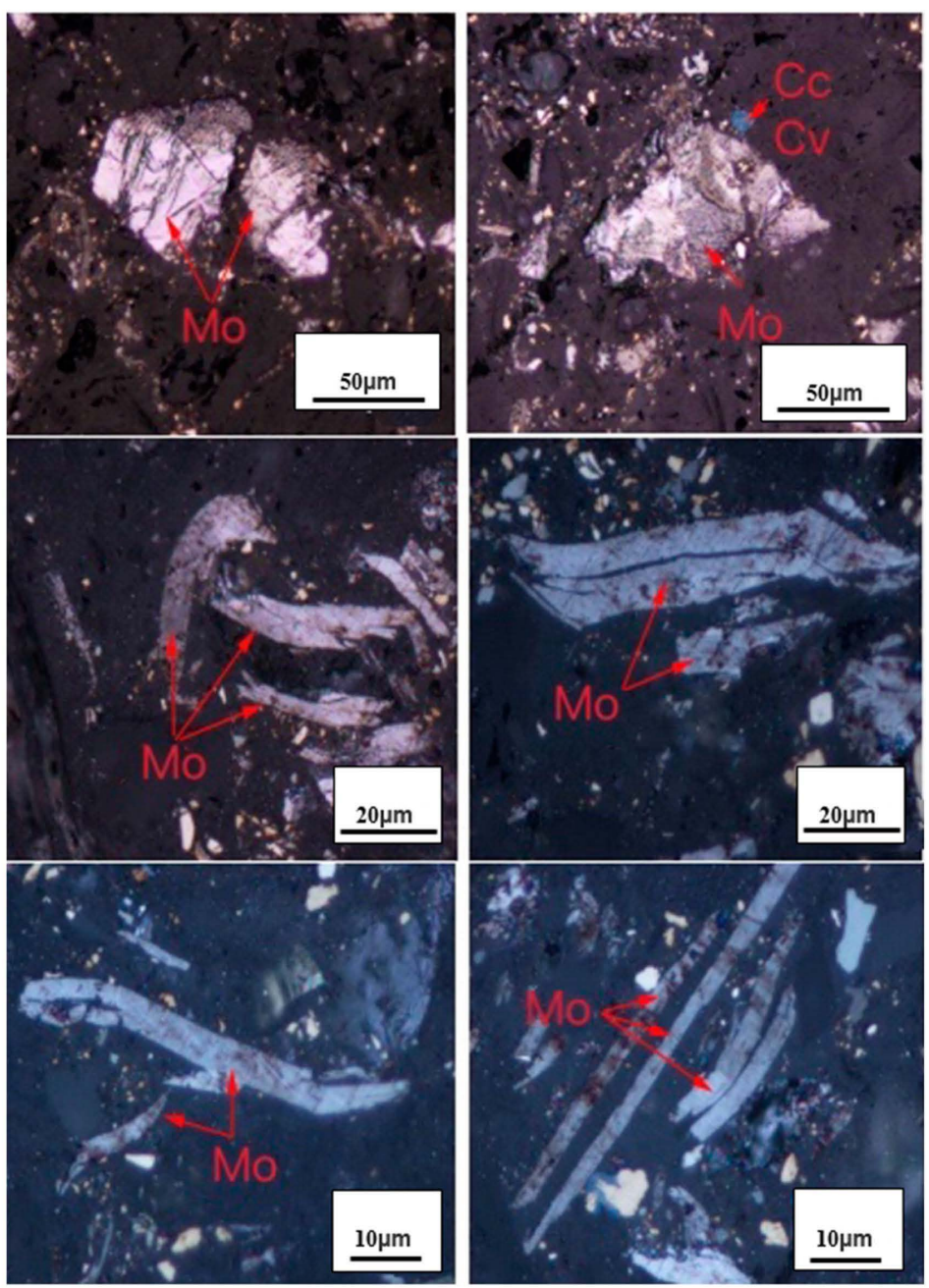

Figure 2. The presence of molybdenite (Mo) and other minerals ( $\mathrm{cv}$ for covellite, $\mathrm{cc}$ for chalcocite) in Mo concentrate.

\section{Experimental Methods}

\subsection{Grinding and Flotation}

The samples for flotation tests were taken from the froth product in the form of slurry at the 4th cleaner stage of molybdenite flotation circuit at the processing operation of Wushan. A complete test procedure consisted of grinding followed by conditioning and flotation of the ground product were conducted immediately after sampling at plant laboratory.

Grinding was carried out in a $\Phi 250 \mathrm{~mm} \times 100 \mathrm{~mm}$ laboratory ball mill. For each grinding test, a slurry sample was added to the ball mill, together with $20 \mathrm{~kg}$ grinding media made up of mild-steel balls. The ground slurry was transferred into a 3 litre volume flotation cell with subsequent conditioning and flotation. The time of this transfer was kept within $30 \mathrm{~min}$. The flowsheet and flotation reagent suite used in the tests are illustrated in Figure 3, where collector and frother are not added because the sampled slurry contained these residue reagents. Copper depressant sodium hydrosulfide (NaHS) was added in accordance with the plant flowsheet and reagent regime. During flotation, the agitation speed was set at $1500 \mathrm{rpm}$, the air flow rate at $15 \mathrm{~L} / \mathrm{min}$. The froth products were collected for $20 \mathrm{~min}$ by scraping into a pan. Plant process water was used in all wet grinding and batch flotation tests carried out in this study. In the study of the depression effect by water glass, middlings are not included for simplification. 


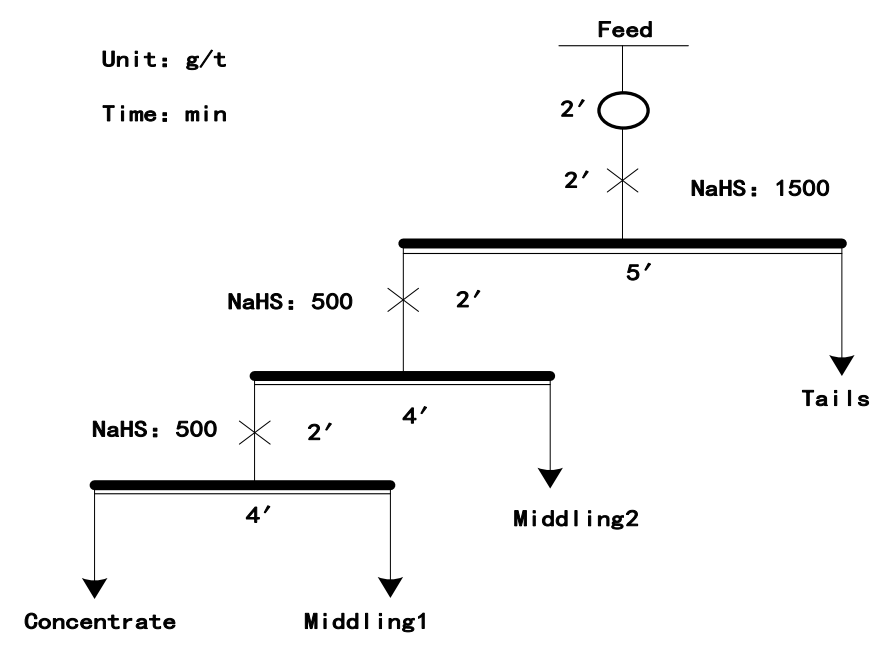

Figure 3. Flowsheet of experimental test in this study.

Samples taken during flotation tests were filtered, dried and weighed before elemental analysis. Representative samples were pulverized into fine powder and analyzed using a Bruker S4 Explorer XRF Spectrophotometer. Particle size distribution and size-by-size analysis of flotation feeds was carried out at the sieve sizes of 325 and 600 mesh.

The following equation was used to determine the recovery of $\mathrm{Cu}, \mathrm{S}, \mathrm{Mo}, \mathrm{SiO}_{2}$ :

$$
\varepsilon=\left(\mathrm{Q}_{\mathrm{k}} \times \beta\right) /\left(\mathrm{Q}_{\mathrm{n}} \times \alpha\right) \times 100 \%
$$

where $\alpha$ and $\beta$ are the percentage weights of the feed and concentrate, respectively; and $Q_{n}$ and $Q_{k}$ are the elemental content of the feed and concentrate.

\subsection{Shell-Isolated Nanoparticle Enhanced Raman Spectroscopy (SHINERS)}

Surface-enhanced Raman scattering (SERS) is a useful analytical technique to study solid-aqueous interfacial phenomenon as it can provide vibrational spectral information of the adsorbed molecules with extremely high sensitivity (with enhancement factor up to $\left.10^{6}\right)$. However, only coinage metals such as $\mathrm{Au}, \mathrm{Ag}$ and $\mathrm{Cu}$ with nanostructure are SERS active. The recently invented shell-isolated nanoparticle enhanced Raman spectroscopy (SHINERS) has overcome the long-standing limitation of SERS [11,12]. In SHINERS, SERSactive nanoparticles are encapsulated by a chemically inert shell. The resulting core-shell nanoparticles (SHINs) are then deposited on any solid substrate. Raman signal from a probe molecule located at the solid surface can then be enhanced, as shown in Figure 4.

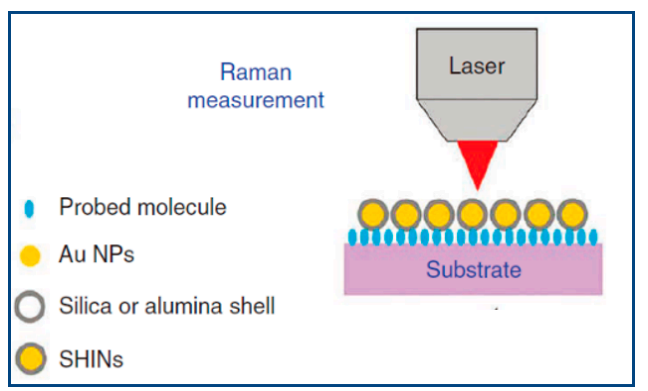

Figure 4. Schematic illustration of shell-isolated nanoparticle enhanced Raman spectroscopy.

An important step for the SHINERS procedure is the synthesis of the core-shell SHINs, typical spherical $\mathrm{Au} @ \mathrm{SiO}_{2}$ with a $55 \mathrm{~nm} \mathrm{Au}$ core and $2 \mathrm{~nm} \mathrm{SiO}_{2}$ shell. In this study, quartz specimen collected from Wushan Mine with cubic geometry was used as and the working side of the specimen was gently abraded with silicon carbide abrasive paper (2000 grits) before further treatment can be applied. A purity of $96.5 \%\left(\mathrm{SiO}_{2}\right.$ content in mass) for the 
specimen was obtained by X-ray florescence (XRF) analysis. The specimen was then rinsed with copious amounts of Milli-Q water, dried in air, deposited with SHINs and rinsed with copious Milli-Q water again. The deposited SHINs particle was very stable without obvious spalling by water rinsing or immersing in analyte. Any probe molecule adsorbed onto silica shell is equivalent to its interaction with quartz minerals as similar surface characteristics between these two materials.

Raman data was collected on a Invia Reflex Raman Microscope (manufactured by Renishaw, Wotton-under-Edge, UK) using a $785 \mathrm{~nm}$ wavelength laser and $1200 \mathrm{line} / \mathrm{mm}$ grating. The SERS spectra were collected using a $50 \times$ long working distance objective lens at a laser power of $25 \mathrm{~mW}$. The exposure time for each spectrum collection was $1 \mathrm{~s}$ with 3 accumulations. The in-situ SHINERS measurements were conducted with a thin reagent-bearing solution covering the surface. The spectrometer was calibrated to the vibrational Raman band of silicon ca. $520 \mathrm{~cm}^{-1}$ prior to the experiment. Normal Raman spectra of pure chemicals were collected with $250 \mathrm{~mW}$ laser power using a 10 s exposure with one accumulation.

\subsection{Focused Beam Reflectance Measurement (FBRM)}

In this investigation, molybdenite specimen and quartz specimen were collected from Wushan Mine, ground to fine particles using mortar pestle. Pre-required volume of slurry was transferred into a $250 \mathrm{~mL}$ glass beaker, giving the targeted solids concentration of 10\%. The FBRM instrument (G400, manufactured by Mettler-Toledo, Columbus, OH, USA) consists of a processing unit and a probe with a $19 \mathrm{~mm}$ diameter tip that has a $14 \mathrm{~mm}$ diameter sapphire window at the end. The FBRM probe was placed into the stirred slurry in a vertical position near the inner wall of the beaker. The slurry was stirred by a four-blade turbine impeller equipped in a dedicated FBRM stand. Stirring rate was set at $400 \mathrm{rpm}$, with the capture of FBRM data recorded in primary mode at $2 \mathrm{~s}$ intervals for total capture time of $10 \mathrm{~min}$. The distributions are presented as curve graphs for ease of comparison but should actually be column graphs. A volume-weighting was achieved by applying a square-weighting to the chord length distribution [13].

According to the mineralogy study, quartz is the most abundant silicate minerals in molybdenum concentrate at Wushan Operation, majorly accounting for the high $\mathrm{SiO}_{2}$ grade of concentrate. Feldspar is the second most abundant silicate minerals at Wushan Operation, and it exhibit similar characteristics in terms of surface properties. Therefore, quartz single mineral specimens were collected from the mine for surface analysis and particle size analysis.

\section{Results and Discussion}

\subsection{Water Quality Analysis}

Flotation is a water-intensive process, in order to minimize the use of freshwater, most mining operations in the world use recycled water, underground water, saline water, or seawater, which contain various inorganic and organic species. The content of these process water from different sites at Wushan plant are routinely measured on a daily basis. Table 6 gives representative analysis data of water quality at Wushan. It is seen that the water recycled to flotation circuit contain quite amount of $\mathrm{Ca}$ (more than $300 \mathrm{mg} / \mathrm{L}$ ), Fe (1 3 mg/L), Cu (5 6 mg/L). Calcium might partially come from the flotation units where alkaline $\mathrm{pH}$ has to be maintained using cost-effective lime $\left(\mathrm{CaO}\right.$ or $\left.\mathrm{Ca}(\mathrm{OH})_{2}\right)$ in order to depress pyrite. Iron is a result of inorganic flocculant added at water treatment plant, supplied by municipal sewage. Acid mine drainage occurs, especially at open pit and tailings dam where iron and copper can be increasingly present. Wushan is located at a high latitude and in a cold region, making the use of sewage water and drainage water necessary in winter and summer, respectively. In general, the water quality at the plant is poor, which may negatively affect the flotation at $\mathrm{Cu}-\mathrm{Mo}$ separation circuit. 
Table 6. Analysis of water quality at Wushan operation.

\begin{tabular}{ccccc}
\hline Samples & $\mathbf{p H}$ & $\mathbf{C u}, \mathbf{m g} / \mathbf{L}$ & $\mathbf{F e}, \mathbf{~ m g} / \mathbf{L}$ & $\mathbf{C a}, \mathbf{m g} / \mathbf{L}$ \\
\hline Tap water 1 & 7.40 & 0.479 & 0.89 & 30.8 \\
Tap water 2 & 7.35 & 0.007 & 0.4 & 28.2 \\
Recycle water 1 & 5.54 & 4.27 & 1.11 & 321 \\
Recycle water 2 & 6.55 & 5.92 & 1.52 & 356 \\
Recycle water 3 & 6.56 & 5.88 & 2.9 & 370 \\
Recycle water 4 & 7.09 & 3.75 & 1.03 & 292 \\
\hline
\end{tabular}

\subsection{Activation of Silicate Minerals Flotation}

It is obvious from process mineralogical data that silicate minerals are mostly liberated with minor interlocking with other sulfides. The access of silicate particles into the molybdenum concentrate could be due to probable flotation processes such as entrainment, slime coating, and most importantly, activation, which are not related to interlocking and degree of liberation. Fine particle entrainment in the froth is a common phenomenon in a lot of flotation situations. However, it does not necessarily imply that they are majorly responsible for the recovery of silicate minerals at Wushan operation, since their mass fraction of -600 mesh is only $16.24 \%$ (Table 2). Overall, the surface properties should be responsible for their inadvertent activation in both bulk flotation circuit and $\mathrm{Cu}-\mathrm{Mo}$ separation flotation circuit.

It is necessary to review the published research where a number of competing factors can be contributing to the flotation behavior of silicate minerals, especially their activation and depression mechanisms. Calcium ions can form colloidal hydroxides, carbonates, and sulfates, depressing the flotation of sulfide minerals using xanthate as collector at a relatively lower $\mathrm{pH}$ [14]. The flotation of molybdenite can also be negatively affected by significantly high concentration of $\mathrm{Ca}^{2+}$ and $\mathrm{Mg}^{2+}$ ions that existing in sea water $[15,16]$. Hirajima et al. [17] and Wisnu-Suyantara et al. [18] reported the depressing effect of $\mathrm{Ca}^{2+}$ ions on the flotation of molybdenite at $\mathrm{pH}>9$, which is possibly due to the adsorption of $\mathrm{CaCO}_{3}$ precipitates on the molybdenite surface. A similar detrimental effect of $\mathrm{Ca}^{2+}$ on molybdenite floatability was reported by Lucay et al. [19] in the presence of sulfate ions. In contrast, the flotation of quartz can usually be activated by calcium ions when sodium oleate is used as collector [8-10]. Moreover, $\mathrm{Fe}(\mathrm{III})$ and $\mathrm{Cu}$ (II) ions preferably activate the flotation of feldspar and quartz when $\mathrm{NaOL}$ is used as collector around pH 7 [20]. These cations adsorb onto mineral surfaces, leading to an expected increase in $\mathrm{NaOL}$ collector adsorption with a subsequent enhancement of flotation recoveries. It has also been reported that quartz can be activated by $\mathrm{Cu}(\mathrm{II})$ and $\mathrm{Ni}(\mathrm{II})$ and floated with xanthate in the $\mathrm{pH} 7 \sim 10$ [21]. In this region, copper hydroxide and nickel hydroxide are stable species precipitating on the surface of silicate minerals, promoting xanthate adsorption. These results indicate the complexity of metal cations effect on the floatability of different minerals in a Cu-Mo ore.

Wushan's bulk flotation circuit involves a combination of collectors which cannot be disclosed. The flotation collectors of copper sulfide minerals becomes more and more novel nowadays, with the main focus being on the application of non-thiol collectors [22]. In this way, the molybdenite concentrate can easily be cleaned to yield a high Mo recovery with a low consumption of $\mathrm{NaHS}$ during $\mathrm{Cu}-\mathrm{Mo}$ separation circuit. The adsorbed molecules can then be easily removed by NaHS from the chalcopyrite surface uncontaminated with thiol collectors, but this may not be easy for $\mathrm{Ca}^{2+}$ activated silicate minerals because the $\mathrm{Ca}^{2+}$ ions are not significantly affected by hydrosulfide ions. Thus, the activated silicate minerals retain their floatability when tranferring from bulk flotation circuit to $\mathrm{Cu}-\mathrm{Mo}$ separation flotation circuit. The recovery of silicate minerals are generally lower than the recovery of copper and molybdenum in the bulk flotation circuit, but silicate recovery can be high at the beginning of Cu-Mo separation flotation circuit (see Table 7). There is a probability distribution of particle-bubble collision and adhesion depending on many affecting factors, of which surface hydrophobicity definitely contributes. The activated and hydrophobic silicate particles are concentrated in bulk circuit and these particles can behave highly probable of collision and 
adhesion at the beginning of molybdenum circuit. In most cases of copper-molybdenum beneficiation plants, the recovery of silicate minerals is low, less than $20 \%$ by using fresh water [23]. The inadvertent activation of silicate minerals in Wushan's case should be a due to the presence of cations in processed water and the recent use of novel copper collectors.

Table 7. Summary of flotation using water glass.

\begin{tabular}{|c|c|c|c|c|c|c|c|c|}
\hline \multirow{2}{*}{ Water Glass, g/t } & \multirow{2}{*}{ Product } & \multirow{2}{*}{ Mass, $\%$} & \multicolumn{3}{|c|}{ Grade, \% } & \multicolumn{3}{|c|}{ Recovery, \% } \\
\hline & & & $\mathrm{Cu}$ & Mo & $\mathrm{SiO}_{2}$ & $\mathrm{Cu}$ & Mo & $\mathrm{SiO}_{2}$ \\
\hline \multirow{3}{*}{0} & Concentrate & 86.95 & 1.100 & 28.140 & 52.39 & 74.79 & 92.55 & 83.72 \\
\hline & Tail & 13.05 & 2.470 & 15.080 & 67.88 & 25.21 & 7.45 & 16.28 \\
\hline & Feed & 100.00 & 1.279 & 26.435 & 54.41 & 100.00 & 100.00 & 100.00 \\
\hline \multirow{3}{*}{500} & Concentrate & 82.63 & 0.970 & 30.760 & 41.53 & 66.74 & 90.70 & 75.01 \\
\hline & Tail & 17.37 & 2.300 & 15.000 & 65.81 & 33.26 & 9.30 & 24.99 \\
\hline & Feed & 100.00 & 1.201 & 28.023 & 45.75 & 100.00 & 100.00 & 100.00 \\
\hline \multirow{3}{*}{1000} & Concentrate & 81.75 & 1.140 & 28.780 & 35.12 & 70.28 & 90.76 & 68.11 \\
\hline & Tail & 18.25 & 2.160 & 13.120 & 69.16 & 29.72 & 9.24 & 31.89 \\
\hline & Feed & 100.00 & 1.326 & 25.923 & 55.93 & 100.00 & 100.00 & 100.00 \\
\hline
\end{tabular}

Moreover, flocculants are also used at Wushan's flotation circuit due to the increasing number of fine particles released by grinding. It is seen from Figure 5 that Wushan's flotation feed contains quite amount of fine chalcopyrite particles less than $10 \mu \mathrm{m}$. Mineralogy shows the mass fraction of $\leq 10 \mu \mathrm{m}$ accounts for $27.58 \%$ of copper minerals and as high as $36.45 \%$ of molybdenum minerals. Low flotation efficiency has been suffered in the beneficiation of low-grade molybdenum ores due to finer size liberation and crystal anisotropy [24,25]. Finer sizes for a high degree of liberation were required for finely disseminated low-grade ores, which reduced the collision and adhesion probabilities of particles to bubbles. As reported, polyethylene oxide (PEO) has been proved to improve flotation efficiency of micro-fine molybdenite particles visibly $[23,26,27]$. Such flocculants adsorbed onto the mineral surface while bridging particles by the hydrophobic long hydrocarbon chain. Thus, flocculants not only induce the flocculation of fine particles but also improve the surface hydrophobicity, both of which improve the flotation performances of molybdenite and chalcopyrite fine particles. However, the selectivity of flocculants is normally poor, anchoring on silicate and other minerals as well $[27,28]$. These minerals can then be activated in the floc-flotation. Moreover, molybdenite and quartz fine particles may induce heterogeneous flocculation, contaminating the concentrate.

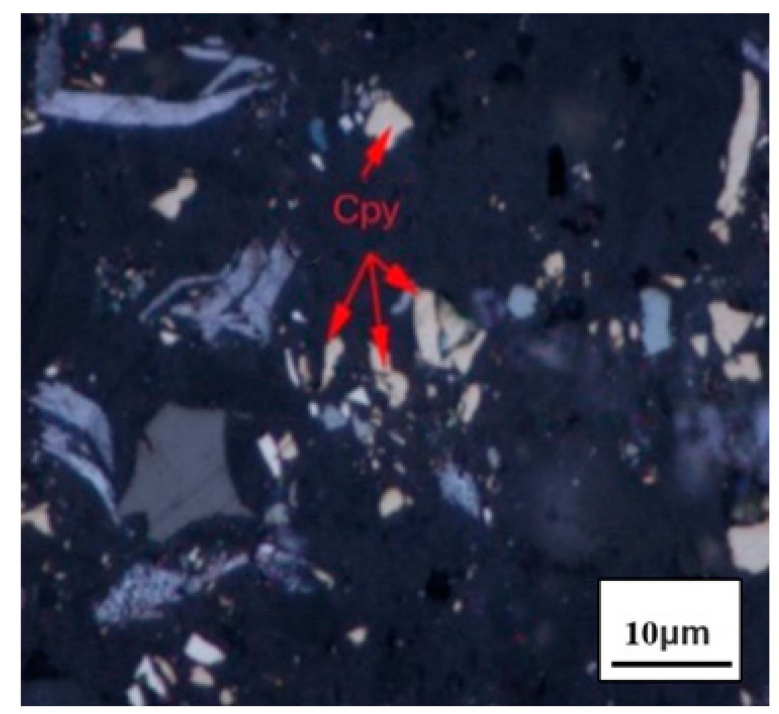

Figure 5. The presence of chalcopyrite (cpy) in bulk concentrate. 


\subsection{Surface Analysis}

In order to prove the proposed hypothesis regarding the inadvertent activation of silicate minerals in flotation, surface properties of typical quartz mineral were analyzed in response to $\mathrm{CaCl}_{2}$ and collectors by using in-situ SHINERS technique.

The normal Raman spectra of bulk quartz sample after dry abrading is shown in Figure 6. The intense Raman bands at $128 \mathrm{~cm}^{-1}, 205 \mathrm{~cm}^{-1}$ and $464 \mathrm{~cm}^{-1}$ are indicative of quartz. For example, the strong peaks at $205 \mathrm{~cm}^{-1}$ and $464 \mathrm{~cm}^{-1}$ can be assigned to Raman active modes of type A1 in quartz crystal. The band at $128 \mathrm{~cm}^{-1}$, corresponds to the Si-O-Si bending vibration, as previously described by Koshchug et al. [29] and Dračínský et al. [30].

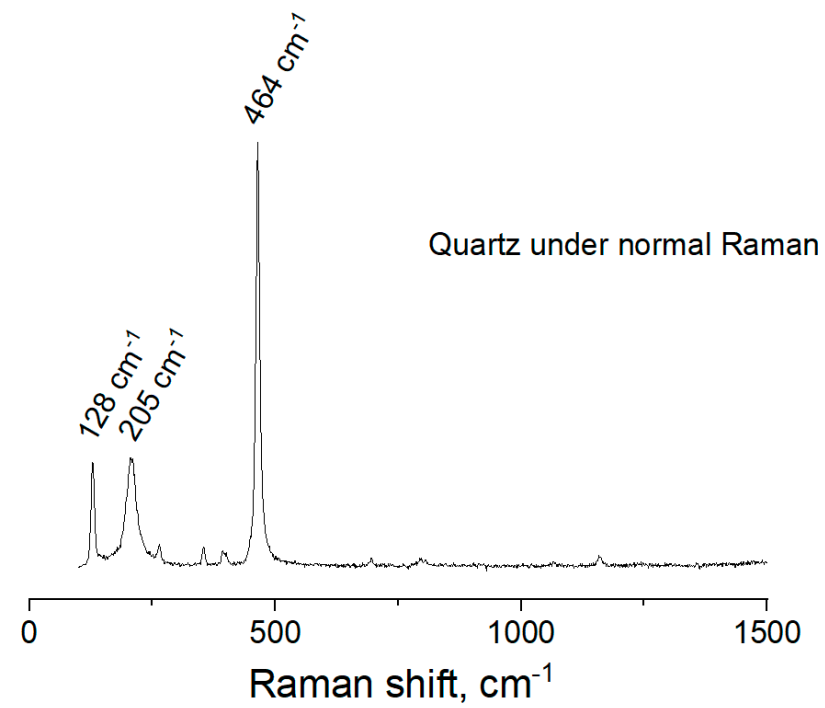

Figure 6. The normal Raman spectra of bulk quartz sample.

The SHINERS spectra of quartz after dry abrading and SHINs deposition is shown in Figure 7. In Figure 7, normal Raman vibrational modes become less obvious in the SHINERS spectra since the SERS signal is a great deal more intense than the bulk mineral signal. The blank sample's spectra in Figure 7 were obtained with Raman laser focusing on SHINs deposited area exposing to air, without any presence of aqueous solution. The peaks at $260 \mathrm{~cm}^{-1}, 455 \mathrm{~cm}^{-1}$ and between $2800 \sim 3000 \mathrm{~cm}^{-1}$, a typical region for hydrocarbon vibrations, are probably corresponding to the adsorbed polluting species. These polluting species exist when sample was exposed to air during pre-treatment and physical adsorption may occur as a result of electrostatic attraction, since the quartz surface is largely negatively charged.

Copper collectors implemented at Wushan Operation include SFJ CIBA and RJ-053. A pre-determined concentration of these collector mixture $\left(10^{-4} \mathrm{M} \mathrm{SFJ} \mathrm{CIBA} \mathrm{and} 10^{-4} \mathrm{M}\right.$ RJ-053) was reacted with the SHINs deposited quartz surface for 20 min before SHINERS spectra can be taken. Upon reaction with the collector mixture, the SHINERS spectra is similar to the blank spectra, indicating the absence of collector adsorption on inactivated quartz surface. The SHINs deposited quartz sample was also treated with $0.005 \mathrm{M} \mathrm{CaCl}_{2}$ solution for $20 \mathrm{~min}$ and subsequently treated with $0.005 \mathrm{M} \mathrm{CaCl}_{2}+10^{-4} \mathrm{M} \mathrm{SFJ} \mathrm{CIBA}+10^{-4}$ M RJ-053 mixture solution for another $20 \mathrm{~min}$. The SHINERS spectra were carried out in-situ with a thin film of corresponding solution covering the sample surface. It is seen from Figure 8 that new peaks appear on the spectra compared to the sample treated with collector only. A full list of Raman bands assignment can be difficult as the molecule structure of the marketed products are unknown. However, the vibrational bands at $1346 \mathrm{~cm}^{-1}, 1378 \mathrm{~cm}^{-1}$ and $2133 \mathrm{~cm}^{-1}$ should be a result of collectors' adsorption onto quartz surface. Moreover, characteristic bands at $215 \mathrm{~cm}^{-1}$ and $455 \mathrm{~cm}^{-1}$ for polluting species are greatly diminished, which is associated with the adsorption of collectors. 


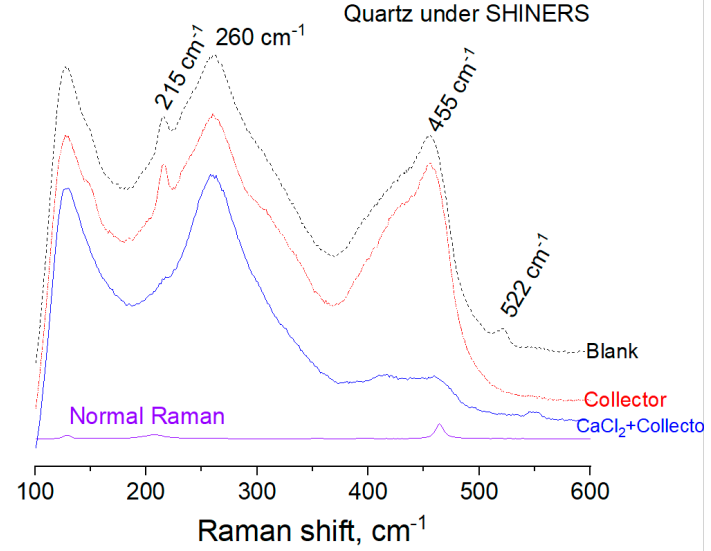

(a)

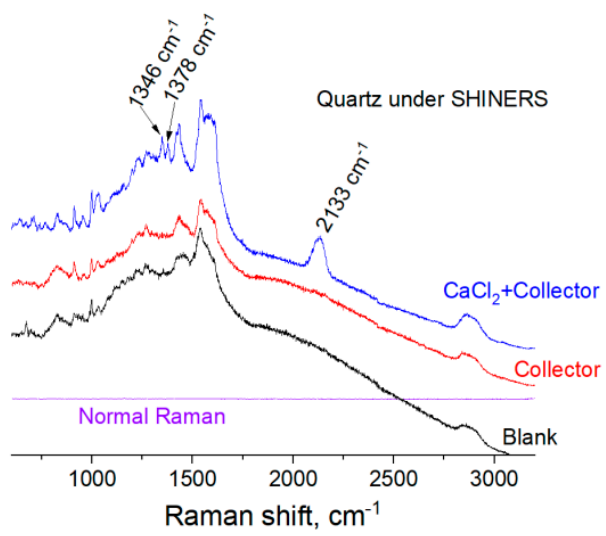

(b)

Figure 7. The SHINERS spectra of bulk quartz sample subjecting to $\mathrm{CaCl}_{2}$ and collector mixture, normal Raman spectra is also included for comparison. (a) spectra at low wavenumbers; (b) spectra at high wavenumbers.

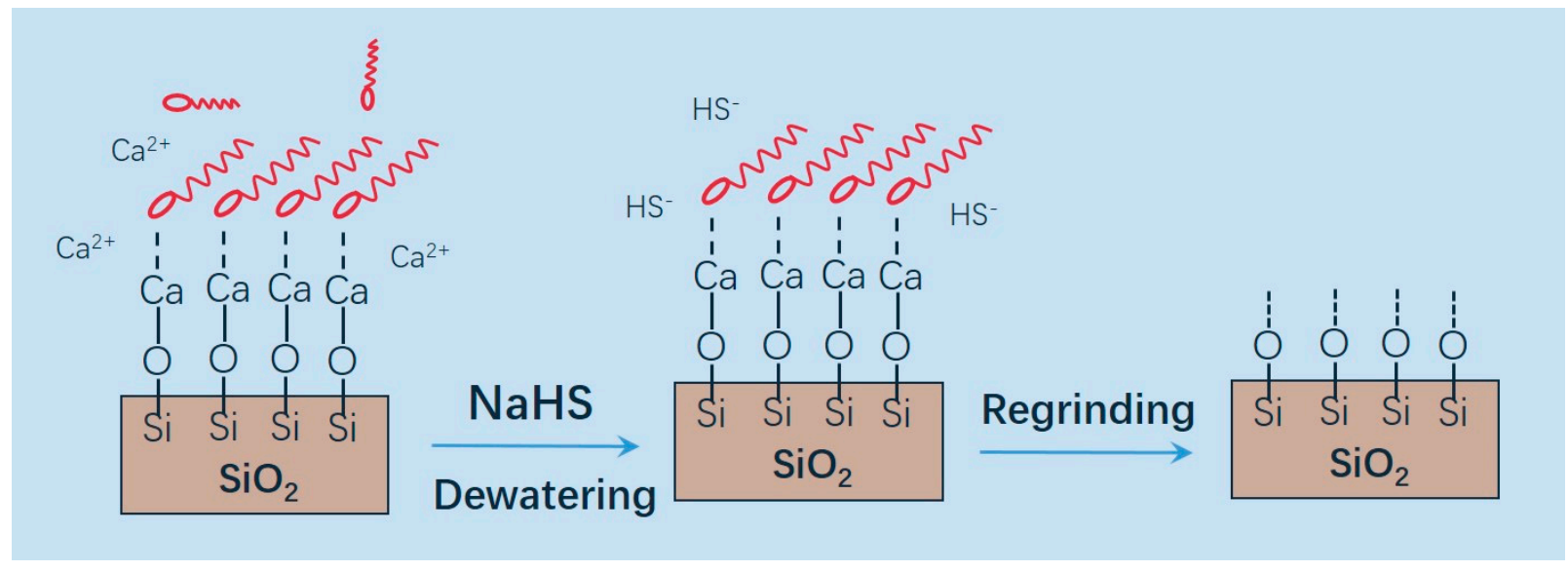

Figure 8. Schematic diagram of $\mathrm{Ca}^{2+}$ and collector jointly activating quartz with subsequent response to NaHS depression and regrinding.

It is implicated that the novel copper collectors at Wushan Operation can also adsorb onto $\mathrm{Ca}^{2+}$-activated quartz, rendering its surface hydrophobic. As $\mathrm{HS}^{-}$does not complex with $\mathrm{Ca}^{2+}$ or quartz, the activated surface can retain its surface hydrophobicity during the process of NaHS depression. According to the water analysis in Table 6, calcium ions concentration was largely higher than iron and copper ions, reasonaly accounting for the activation of silicate minerals. Mechanical damage during regrinding may remove the surface layer, in addition to particle size reduction. The proposed mechanism of quartz activation and depression is schematically illustrated in Figure 8.

\subsection{Depression by Water Glass}

Sodium silicate solution (commonly known as water glass) is a typical depressant for silicate minerals' flotation [31-33]. Molecular dynamics simulations and density functional theory calculations demonstrated that water glass formed a dense adsorption layer on quartz, with both strong hydrogen bond and covalent bond being the main driving forces for adsorption [34]. The stable adsorption layer prevents $\mathrm{Ca}^{2+}, \mathrm{Mg}^{2+}$, and collectors from contacting quartz. Meanwhile, adsorption increases the electronegativity of quartz particles and enhances their dispersion. The aggregation between valuable minerals and fine gangue minerals can then be greatly reduced, avoiding the deterioration of concentrate grade.

The rougher flotation tests carried out are summarized in Table 7. Adding appropriate amount of water glass is beneficial to reduce silica in the concentrate without compromising 
molybdenum recovery too much. The silica grade of molybdenum concentrate is reduced from $52.39 \%$ to $35.12 \%$ by merely using rougher flotation and the quality of molybdenum concentrate could be further improved if cleaner stage is included.

\subsection{Depression by Regrinding}

As presented in the process flowsheet, the regrind mill is operating in open circuit. Open circuit grinding is very well-known for producing a flat size distribution with a lot of unnecessary ultra-fines. It is seen from Table 8 that regrinding for 2 min only makes a mass fraction of -325 mesh increasing from $34 \%$ to $50 \%$, while the silica content in molybdenum concentrate has been effectively reduced. Molybdenum grade in the concentrate after one stage of rougher and two stages of cleaner operation has been increased to $41.96 \%$, which is $3.79 \%$ higher than that without regrinding. It is also seen that the recovery of molybdenite and the mass recovery slightly decreased to some extent, compromising the separation efficiency. Therefore, great caution needs to be taken for the use of regrinding in molybdenum circuit.

Table 8. Data sheet of cleaner flotation using regrinding.

\begin{tabular}{|c|c|c|c|c|c|c|c|c|c|c|}
\hline & \multirow{2}{*}{ Product } & \multirow{2}{*}{ Mass, $\%$} & \multicolumn{4}{|c|}{ Grade, \% } & \multicolumn{4}{|c|}{ Recovery, \% } \\
\hline & & & $\mathrm{Cu}$ & Mo & $\mathrm{SiO}_{2}$ & $S$ & $\mathrm{Cu}$ & Mo & $\mathrm{SiO}_{2}$ & S \\
\hline \multirow{5}{*}{$\begin{array}{l}\text { Without } \\
\text { regrinding } \\
(-325=34 \%)\end{array}$} & Concentrate & 53.46 & 0.46 & 38.17 & 49.08 & 22.77 & 25.74 & 67.34 & 45.78 & 64.79 \\
\hline & Middling1 & 8.84 & 1.15 & 27.06 & 58.97 & 18.60 & 10.64 & 7.89 & 9.09 & 8.75 \\
\hline & Middling2 & 13.37 & 1.18 & 25.53 & 64.76 & 15.50 & 16.51 & 11.26 & 15.10 & 11.03 \\
\hline & Tail & 24.33 & 1.85 & 16.83 & 70.73 & 11.92 & 47.11 & 13.51 & 30.02 & 15.43 \\
\hline & Feed & 100.00 & 0.96 & 30.31 & 57.32 & 18.79 & 100.00 & 100.00 & 100.00 & 100.00 \\
\hline \multirow{5}{*}{$\begin{array}{c}\text { With } \\
\text { regrinding } \\
(-325=50 \%)\end{array}$} & Concentrate & 46.14 & 0.48 & 41.96 & 43.69 & 26.48 & 18.65 & 63.34 & 37.50 & 63.00 \\
\hline & Middling1 & 5.66 & 1.32 & 30.56 & 51.82 & 21.78 & 6.29 & 5.66 & 5.45 & 6.35 \\
\hline & Middling2 & 12.97 & 1.33 & 30.91 & 50.48 & 18.42 & 14.53 & 13.12 & 12.18 & 12.32 \\
\hline & Tail & 35.23 & 2.04 & 15.51 & 68.46 & 10.09 & 60.53 & 17.88 & 44.87 & 18.33 \\
\hline & Feed & 100.00 & 1.19 & 30.56 & 53.76 & 19.39 & 100.00 & 100.00 & 100.00 & 100.00 \\
\hline
\end{tabular}

In the grinding process, both abrasion/attrition and breakage could be the mechanisms of comminution actions taking place. Attrition may be helpful to obtain freshly fractured surface without reducing particle size too much [35]. The contaminated silicate mineral particles surface can then be cleaned, exhibiting their naturally owned hydrophilic characteristics. Size-by-size analysis of the feed in Table 9 indicates molybdenite particle size is slightly reduced as +325 mesh mass fraction decreasing from $43.00 \%$ to $36.96 \%$, while its mass fraction of -600 mesh remains unchanged. However, silicate particle size significantly reduced as +325 mesh mass fraction decreasing from $84.10 \%$ to $62.98 \%$. In particular, the mass fraction of -600 mesh increased from $4.64 \%$ to $14.18 \%$. The size-by-size analysis implicates that silicate minerals are easier to grind compared to molybdenite. The blade-shaped grains of molybdenite are largely restored in grinding.

Table 9. Size by size analysis of feed using regrinding.

\begin{tabular}{|c|c|c|c|c|c|c|c|c|c|c|}
\hline & \multirow{2}{*}{ Mesh } & \multirow{2}{*}{ Mass, $\%$} & \multicolumn{4}{|c|}{ Grade, \% } & \multicolumn{4}{|c|}{ Metal Distribution, \% } \\
\hline & & & $\mathrm{Cu}$ & Mo & $\mathrm{SiO}_{2}$ & S & $\mathrm{Cu}$ & Mo & $\mathrm{SiO}_{2}$ & $\mathrm{~S}$ \\
\hline \multirow{4}{*}{$\begin{array}{l}\text { Without } \\
\text { regrinding }\end{array}$} & +325 & 65.06 & 0.63 & 18.07 & 73.47 & 44.28 & 42.54 & 43 & 84.1 & 44.28 \\
\hline & $325 \sim 600$ & 16.27 & 1.05 & 39.09 & 39.33 & 22.93 & 17.73 & 23.25 & 11.26 & 22.93 \\
\hline & -600 & 18.67 & 2.05 & 49.41 & 14.13 & 32.78 & 39.73 & 33.75 & 4.64 & 32.78 \\
\hline & Sum & 100.00 & 0.96 & 27.34 & 56.84 & 100.00 & 100 & 100 & 100 & 100 \\
\hline \multirow{4}{*}{$\begin{array}{l}\text { With } \\
\text { regrinding }\end{array}$} & +325 & 49.80 & 0.49 & 21.42 & 70.89 & 35.80 & 23.81 & 36.96 & 62.98 & 35.8 \\
\hline & $325 \sim 600$ & 24.77 & 0.74 & 34.68 & 51.70 & 29.02 & 17.89 & 29.76 & 22.84 & 29.02 \\
\hline & -600 & 25.43 & 2.35 & 37.77 & 31.27 & 35.18 & 58.3 & 33.27 & 14.18 & 35.18 \\
\hline & Sum & 100.00 & 1.02 & 28.86 & 56.06 & 100.00 & 100 & 100 & 100 & 100 \\
\hline
\end{tabular}


Most minerals exhibit the typical size dependent recovery as illustrated by Trahar [36] with the maximum recovery being achieved in the intermediate size fractions and the coarse and fine particles being recovered at a lower rate. For both molybdenum and copper, their recoveries are highest in the range of 20 150 $\mu \mathrm{m}$ [36]. In the case of molybdenum, the finer than $20 \mu \mathrm{m}$ fraction recovers 10\% lower than the optimum size range. The more fine silicate mineral particles that grinding produces, the more difficult their flotation. In contrast, the effects of grinding on molybdenite particle size and the subsequent flotation performance are insignificant.

Flocculants has a prominent effect in the microfine molybdenite flotation. In addition, kerosene not only acts at collector, but also induce the formation of large flocs due to the hydrophobic force attraction between molybdenite fine particles. The advanced FBRM instrument can give an online measurement of particle size, rendering flocculation study easier. As seen in Figure 9, molybdenite fine particles exhibited a mean chord length of $26 \mu \mathrm{m}$ before the addition of any reagent, but it increased to $75 \mu \mathrm{m}$ shortly after the addition of $0.35 \mathrm{~g} / \mathrm{L}$ kerosene. Figure 10 shows that, in square weighted mode, large flocs above average chord length are commonly seen. These molybdenite flocs are easily floated onto the surface of slurry even without the presence of dedicated bubbling. The high points of chord length in Figure 9 were obtained when FBRM probe was lifted adjacent to the surface of slurry, where large flocs are concentrated. Flocs of quartz particles were hardly seen with the addition of kerosene, in accordance with the unchanged mean chord length and its distribution as shown in Figures 9 and 10, respectively.
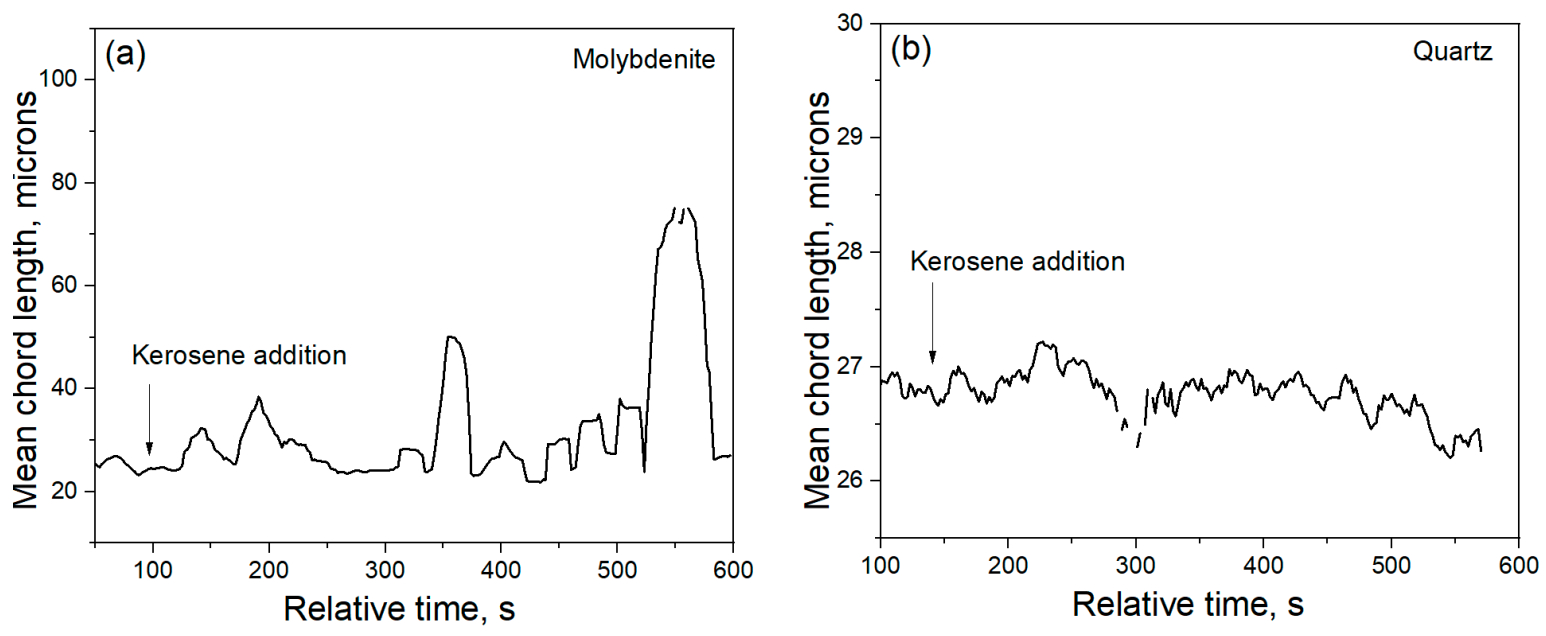

Figure 9. Flocculation kinetics of molybdenite (a) and quartz (b) particles in response to kerosene addition (0.35 g/L).
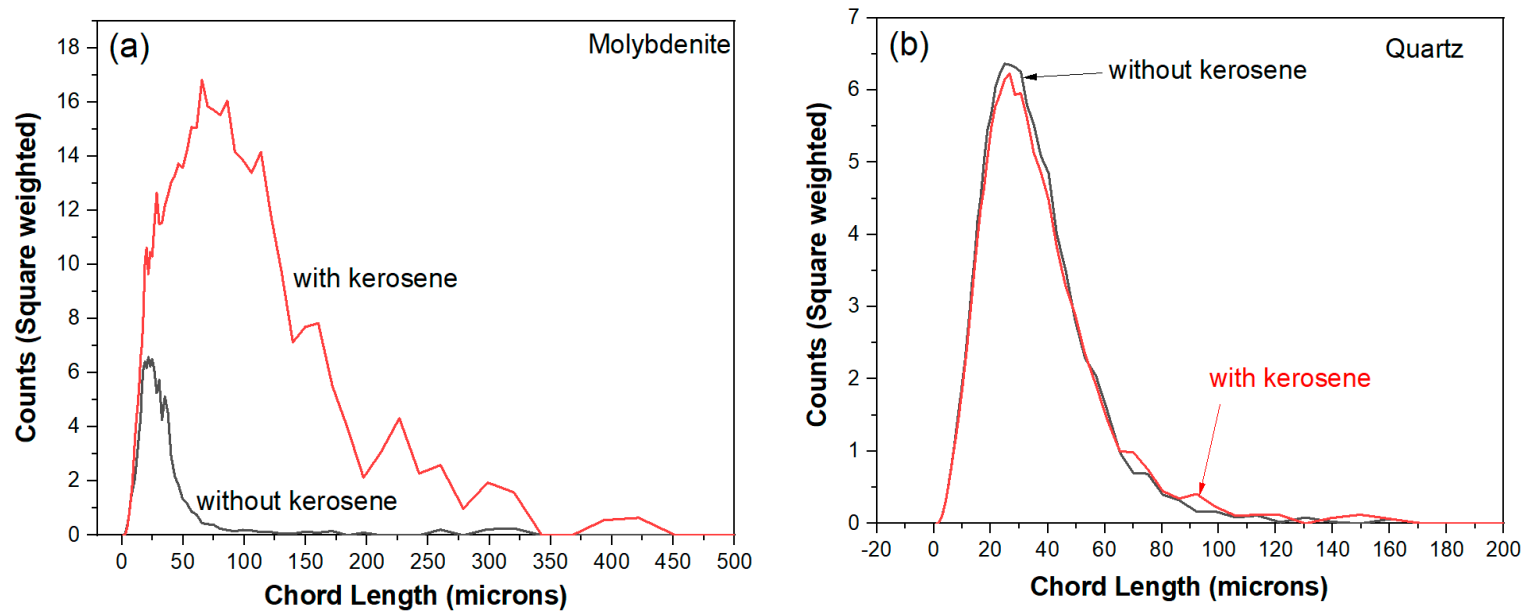

Figure 10. Chord length distribution of molybdenite (a) and quartz (b) particles in response to kerosene addition ( $0.35 \mathrm{~g} / \mathrm{L})$. 
Hydrophilic silicate mineral particles are not prone to be attractive to each other, therefore flocculation can hardly occur between these particles. The flocs size is conducive to the flotation of microfine molybdenite, leading to enhanced selectivity against silicate minerals. In conclusion, slightly regrinding is beneficial for improving the quality of molybdenum concentrate for two main reasons: firstly, the exposure of nature hydrophilic silicate particle surface upon attrition. Secondly, relatively finer silicate particles lead to poorer recovery. The different particle size was due to differences of grindability between molybdenite and quartz, in addition to flocculation between molybdenite and silicate minerals. The different performances of quartz and molybdenite particles subjecting to regrinding and kerosene are schematically illustrated in Figure 11 for better understanding.

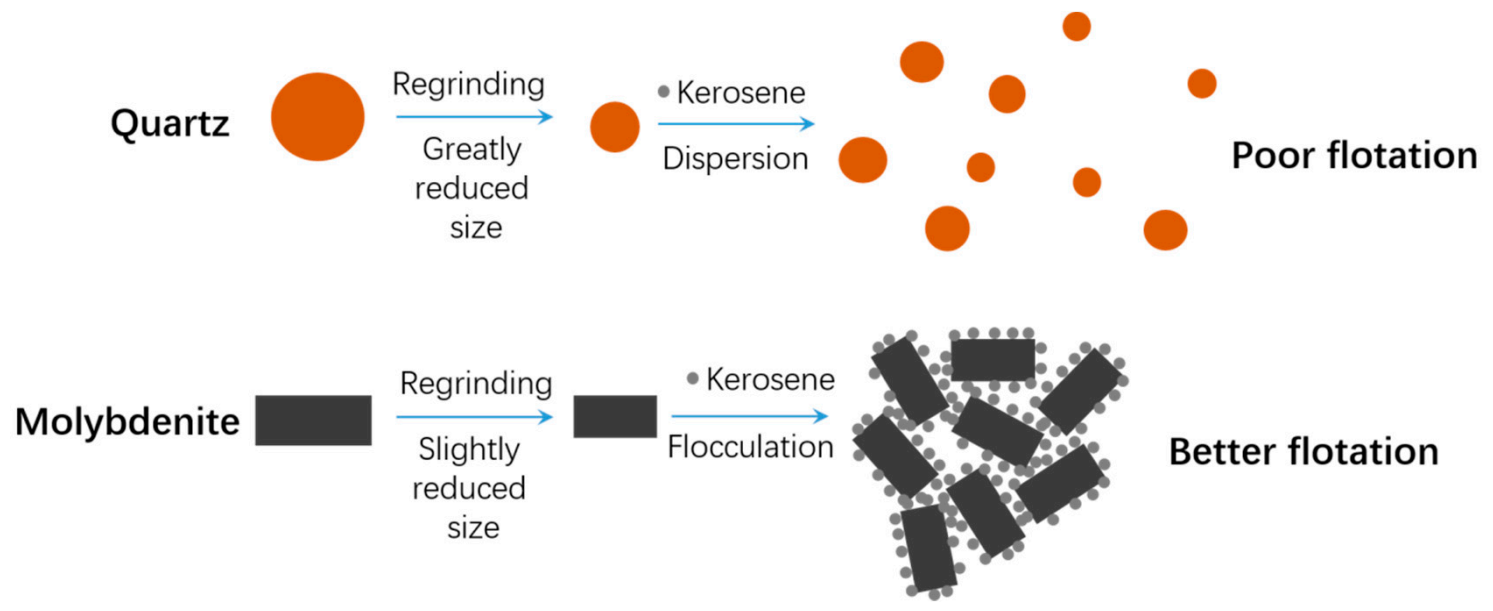

Figure 11. Schematic diagram of fine quartz and molybdenite particles and their performance subjecting to regrinding and kerosene.

\section{Practices with Process Optimization}

Several operational changes have been made to capitalize on the findings of the research these include water glass and regrinding to depress problematic silicate minerals. Before optimization, the molybdenum grade of concentrate product averaged at $42.28 \%$. After the optimization, the molybdenum grade reached as high as $46.40 \%$, and the qualified rate increased from $20.48 \%$ to $68.60 \%$, as shown in Table 10 .

Table 10. Comparison of plant performance before and after process optimization.

\begin{tabular}{cccc}
\hline & \multirow{2}{*}{ Qualified Rate, \% } & \multicolumn{2}{c}{ Qualified Mo Concentrate } \\
\cline { 3 - 4 } & & Cu Grade, \% & Mo Grade, \% \\
\hline Before optimization & 20.48 & 1.54 & 42.28 \\
After optimization & 68.60 & 1.12 & 46.40 \\
\hline
\end{tabular}

\section{Conclusions}

Unqualified molybdenum concentrate $(\leq 45 \% \mathrm{Mo})$ has been continuously encountered over a period at Wushan copper-molybdenum plant with the problem of coarse silicate minerals transferring into molybdenum flotation concentrate. Process mineralogy and water quality analysis from this period indicated that silicate minerals were inadvertently activated in flotation. The activation of silicate minerals is probably due to the adsorption of divalent metal cations which render their surface hydrophobic upon interaction with novel collectors, as evidenced by advanced in-situ surface analysis. The addition of water glass and the implementation of regrinding at cleaner stage of $\mathrm{Cu}-\mathrm{Mo}$ separation flotation circuit were found to be effective in depressing silicate mineral flotation and improving the quality of molybdenum production at Wushan Operation. Regrinding is beneficial to obtain a clean and hydrophilic surface. It also leads to finer silicate mineral particles and, consequently, a 
poorer recovery compared to molybdenite. The presence of kerosene induces flocculation of molybdenite particles, enhancing their tolerance in fine particle flotation.

Author Contributions: Conceptualization, Y.M., T.L. and B.G.; methodology, Y.M. and B.G.; formal analysis, Y.M., W.Z. and B.G.; investigation, F.L. and J.W.; data curation, Y.M. and W.Z.; writingoriginal draft preparation, Y.M.; writing-review and editing, W.Z. and B.G.; visualization, Y.M. and B.G.; supervision, J.W. All authors have read and agreed to the published version of the manuscript.

Funding: This research received no external funding.

Institutional Review Board Statement: Not applicable.

Informed Consent Statement: Not applicable.

Acknowledgments: This research is supported by the Department of Production and Technology, China National Gold Group Inner Mongolia Mining Co., Ltd. Fuzhou University Testing Fund of precious apparatus (project No. 2020T039) is also appreciated.

Conflicts of Interest: The authors declare no conflict of interest.

\section{References}

1. Chen, Y.; Chen, X.; Peng, Y. The effect of sodium hydrosulfide on molybdenite flotation as a depressant of copper sulfides. Miner. Eng. 2020, 148, 106203. [CrossRef]

2. Pearse, M.J. An overview of the use of chemical reagents in mineral processing. Miner. Eng. 2005, 18, 139-149. [CrossRef]

3. Yan, H.; Yang, B.; Zhu, H.; Huang, P.; Hu, Y. Selective flotation of Cu-Mo sulfides using dithiothreitol as an environmental-friendly depressant. Miner. Eng. 2021, 168, 106929. [CrossRef]

4. Yi, G.; Macha, E.; Dyke, J.V.; Macha, R.E.; McKay, T.; Free, M.L. Recent progress on research of molybdenite flotation: A review. Adv. Colloid. Interface Sci. 2021, 295, 102466. [CrossRef] [PubMed]

5. Yin, Z.; Sun, W.; Hu, Y.; Zhai, J.; Guan, Q. Evaluation of the replacement of NaCN with depressant mixtures in the separation of copper-molybdenum sulphide ore by flotation. Sep. Purif. Technol. 2017, 173, 9-16. [CrossRef]

6. Abdollahi, M.; Bahrami, A.; Mirmohammadi, M.S.; Kazemi, F.; Danesh, A.; Ghorbani, Y. A process mineralogy approach to optimize molybdenite flotation in copper-molybdenum processing plants. Miner. Eng. 2020, 157, 106557. [CrossRef]

7. Triffett, B.; Veloo, C.; Adair, B.J.I.; Bradshaw, D. An investigation of the factors affecting the recovery of molybdenite in the Kennecott Utah Copper bulk flotation circuit. Miner. Eng. 2008, 21, 832-840. [CrossRef]

8. Gao, Z.; Jiang, Z.; Sun, W.; Gao, Y. Typical roles of metal ions in mineral flotation: A review. Trans. Nonferr. Metal. Soc. 2021, 31, 2081-2101. [CrossRef]

9. Wang, Y.; Khoso, S.; Luo, X.; Tian, M. Understanding the depression mechanism of citric acid in sodium oleate flotation of $\mathrm{Ca}^{2+}$-activated quartz: Experimental and DFT study. Miner. Eng. 2019, 140, 105878. [CrossRef]

10. Xie, R.; Zhu, Y.; Liu, J.; Li, Y. Effects of metal ions on the flotation separation of spodumene from feldspar and quartz. Miner. Eng. 2021, 168, 106-931. [CrossRef]

11. Anema, J.R.; Li, J.; Yang, Z.; Ren, B.; Tian, Z. Shell-isolated nanoparticle-enhanced Raman spectroscopy: Expanding the versatility of surface-enhanced Raman scattering. Rev. Anal. Chem. 2011, 4, 129-150. [CrossRef] [PubMed]

12. Li, J.; Huang, Y.; Ding, Y.; Zhang, Z.; Zhou, Z.; Wu, D.; Ren, B.; Wang, Z.; Tian, Z. Shell-isolated nanoparticle-enhanced Raman Spectroscopy. Nature 2010, 464, 392. [CrossRef]

13. Grabsch, A.F.; Yahyaei, M.; Fawell, P.D. Number-sensitive particle size measurements for monitoring flocculation responses to different grinding conditions. Miner. Eng. 2020, 145, 06088. [CrossRef]

14. Zanina, M.; Lambertc, H.; du Plessis, C.A. Lime use and functionality in sulphide mineral flotation: A review. Miner. Eng. 2019, 143, 105922. [CrossRef]

15. Chen, Y.; Chen, X.; Peng, Y. The effect of sodium hydrosulfide on molybdenite flotation in seawater and diluted seawater. Miner. Eng. 2020, 158, 106589. [CrossRef]

16. Qiu, Z.; Liu, G.; Liu, Q.; Zhong, H. Understanding the roles of high salinity in inhibiting the molybdenite flotation. Colloids Surf. 2016, 509, 123-129. [CrossRef]

17. Hirajima, T.; Wisnu-Suyantara, G.P.; Ichikawa, O.; Elmahdy, A.M. $\mathrm{Mg}^{2+}$ and $\mathrm{Ca}^{2+}$ as divalent seawater cations on the floatability of molybdenite and chalcopyrite. Miner. Eng. 2016, 96-97, 83-93. [CrossRef]

18. Wisnu-Suyantara, G.P.; Hirajima, T.; Miki, H.; Sasaki, K. Floatability of molybdenite and chalcopyrite in artificial seawater. Miner. Eng. 2018, 115, 117-130. [CrossRef]

19. Lucay, F.; Cisternas, L.A.; Gálvez, E.; López-Valdivieso, A. Study of the natural floatability of molybdenite fines in saline solutions and effect of gypsum precipitation. Miner. Metall. Explor. 2015, 32, 203-208. [CrossRef]

20. Zhang, J.; Wang, W.; Liu, J.; Huang, Y.; Feng, Q.; Zhao, H. Fe(III) as an activator for the flotation of spodumene, albite, and quartz minerals. Miner. Eng. 2014, 61, 16-22. 
21. Fornasiero, D.; Ralston, J. Cu(II) and Ni(II) activation in the flotation of quartz, lizardite and chlorite. Int. J. Miner. Process. 2005, 76, 75-81. [CrossRef]

22. Liu, G.; Lu, Y.; Zhong, H.; Cao, Z.; Xu, Z. A novel approach for preferential flotation recovery of molybdenite from a porphyry copper-molybdenum ore. Miner. Eng. 2012, 36-38, 37-44. [CrossRef]

23. Li, S.; Ma, X.; Wang, J.; Xing, Y.; Gui, X.; Cao, Y. Effect of polyethylene oxide on flotation of molybdenite fines. Miner. Eng. 2020 146, 106146. [CrossRef]

24. Castro, S.; Lopez-Valdivieso, A.; Laskowski, J.S. Review of the flotation of molybdenite. Part I: Surface properties and floatability. Int. J. Miner. Process. 2016, 148, 48-58. [CrossRef]

25. Zanina, M.; Ametov, I.; Grano, S.; Zhou, L.; Skinner, W. A study of mechanisms affecting molybdenite recovery in a bulk copper/molybdenum flotation circuit. Int. J. Miner. Process. 2009, 93, 256-266. [CrossRef]

26. Alvarez, A.; Gutierrez, L.; Laskowski, J.S. Use of polyethylene oxide to improve flotation of fine molybdenite. Miner. Eng. 2018, 127, 232-237. [CrossRef]

27. Li, S.; Gao, L.; Wang, J.; Zhou, H.; Liao, Y.; Xing, Y.; Gui, X.; Gao, Y. Polyethylene oxide assisted separation of molybdenite from quartz by flotation. Miner. Eng. 2021, 162, 106765. [CrossRef]

28. Tian, J.; Gao, H.; Guan, J.; Ren, Z. Modified floc-flotation in fine sericite flotation using polymethylhydrosiloxane. Sep. Purif. Technol. 2017, 174, 439-444. [CrossRef]

29. Koshchug, D.G.; Koshlyakova, A.N.; Balitsky, V.S.; Vyatkin, S.V. Infrared and Raman spectroscopy study of $\mathrm{Si}_{1-x} \mathrm{GexO}_{2}$ solid solutions with $\alpha$-quartz structures. Spectrochim. Acta A 2020, 233, 118168. [CrossRef]

30. Dračínský, M.; Benda, L.; Bouř, P. Ab initio modeling of fused silica, crystal quartz, and water Raman spectra. Chem. Phys. Lett. 2011, 215, 54-59. [CrossRef]

31. Abaka-Wood, G.B.; Addai-Mensah, J.; Skinner, W. Selective flotation of rare earth oxides from hematite and quartz mixtures using oleic acid as a collector. Int. J. Miner. Process. 2017, 169, 60-69. [CrossRef]

32. Rao, D.S.; VijayaKumar, T.V.; Rao, S.S.; Prabhakar, S.; Raju, G.B. Effectiveness of sodium silicate as gangue depressants in iron ore slimes flotation. Int. J. Miner. Metall. Mater. 2011, 18, 515-522. [CrossRef]

33. Tohry, A.; Dehghani, A. Effect of sodium silicate on the reverse anionic flotation of a siliceous-phosphorus iron ore. Sep. Purif. Technol. 2016, 164, 28-33. [CrossRef]

34. Hao, H.; Cao, Y.; Li, L.; Fan, G.; Liu, J. Dispersion and depression mechanism of sodium silicate on quartz: Combined molecular dynamics simulations and density functional theory calculations. Appl. Surf. Sci. 2021, 537, 147926. [CrossRef]

35. Chen, X.; Peng, Y.; Bradshaw, D. The effect of particle breakage mechanisms during regrinding on the subsequent cleaner flotation. Miner. Eng. 2014, 66-68, 157-164. [CrossRef]

36. Trahar, W.J. A rational interpretation of the role of particle size in flotation. Int. J. Miner. Process. 1981, 8, 289-327. [CrossRef] 